\title{
Traduções, diálogos e (des)construções: a crítica feminista em quatro tempos
}

Traduções da Cultura: perspectivas críticas feministas (1970-2010). BRANDÃO, Izabel; CAVALCANTI, Ildney; COSTA; Claudia de Lima; LIMA, Ana Cecília Acioli. (Orgs.).

Florianópolis: EDUFAL; Editora da UFSC, 2017.

\begin{abstract}
O Grupo de Trabalho A Mulher na Literatura, da Associação Nacional de Pós-Graduação e Pesquisa em Letras e Linguística - ANPOLL, está comemorando três décadas de existência, sedimentadas a partir de um trabalho que privilegia o resgate, 0 reconhecimento e 0 estudo da produção literária e cultural de autoria feminina. E é nessa atmosfera celebrativa que a antologia Traduções da Cultura: perspectivas críticas feministas (1970-2010) chega às mãos de pesquisadoras/es feministas brasileiras/os, com 840 páginas, segmentada em 21 artigos, que foram e continuam sendo referência para as pesquisas no âmbito da crítica feminista e dos estudos de gênero e queer no país.

A obra, organizada pelas professoras e pesquisadoras Izabel Brandão, Ildney Cavalcanti, Ana Cecília Acioli Lima e Claudia de Lima Costa, respectivamente, das Universidades Federais de Alagoas e de Santa Catarina, é o resultado de um projeto nominado "Traduções da cultura: uma antologia interdisciplinar nas interfaces entre estudos de gênero, feminismos e mulheres", idealizado numa das reuniões da ANPOLL, mais precisamente, durante o ENANPOLL de 2010 , ocorrido na Universidade Federal de Minas Gerais. A proposta estabelecida pelo GT - e habilmente corporificada no referido livro - era a de viabilizar uma antologia composta por traduções de ensaios acadêmicos produzidos em língua inglesa, francesa e espanhola, no decorrer de quatro décadas (de 1970 a 2010), tendo em vista a proficuidade desse período no amadurecimento da crítica feminista, no reconhecimento do gênero e das suas interseccionalidades, assim como na compreensão do queer.

Todas essas informações contextuais foram cuidadosamente inseridas na apresentação do livro. São mais de 40 páginas introdutórias, responsáveis por situar o/a leitor/a acerca das motivações para o desenvolvimento do projeto e da metodologia empregada, mas, principalmente, da abordagem e do impacto de cada texto selecionado para integrar o volume. As organizadoras expressam o desejo de que a antologia seja útil para estudantes ainda na graduação, o que é viabilizado pela forma com que o trabalho foi conduzido. Ao
\end{abstract}


passo que se mostra absolutamente significativo para pesquisadoras/es experientes na abordagem - sobretudo por agrupar, em um único material, produções situadas em temposespaços diversificados -, é cuidadoso no trato de informações importantes para quem está iniciando os estudos dirigidos à crítica feminista e às questões de gênero.

Três estratégias contribuem para isso: o caráter didático da apresentação; as notas da tradutora que, além de trazerem informações contextuais básicas e detalhes sobre o processo de tradução, fundamentais para a apreensão do conteúdo, traçam um paralelo com o trabalho desenvolvido por pesquisadoras do $\mathrm{GT}$, demonstrando a afinidade entre o que estava sendo debatido no exterior e as pesquisas desenvolvidas no Brasil; e, por último, os comentários, ao final de cada ensaio, já que trazem fatos relevantes sobre a trajetória acadêmica das autoras, o contexto do ensaio traduzido e a atualização do texto, i. e., em que aspectos continua dialogando com as discussões mais recentes.

Nesse sentido, é expressiva a quantidade de pesquisadoras - e um pesquisador -, de diferentes regiões do país e do exterior, mobilizadas para a elaboração desses comentários, sendo elas - e ele -, além das próprias organizadoras, que também traduziram: Susana Bornéo Funck, Cecilia Sardenberg, Luciana Eleonora Deplagne, Cintia Schwantes, Eliane Campello, Rita Terezinha Schmidt, Eliane de Souza Ávila, Miriam Adelman, Milena Costa de Souza, Keisha-Khan Y. Perry, Sandra Regina Goulart Almeida, Zahidé Lupinacci Muzart, Simone Pereira Schmidt, Carla Rodrigues, Maria Aparecida Andrade Salgueiro e José Gatti.

Algumas das produções selecionadas já haviam sido traduzidas e veiculadas no Brasil, como é o caso de dois artigos da década de 1970: "Está a mulher para o homem assim como a natureza para a cultura?", da estadunidense Sherry B. Ortner, incluída na coletânea Women, Culture and Society (1974) - coordenada por Michelle Zimbalist Rosalvo e Louise Lamphere -, que foi traduzida para o português em 1979, e "Prazer visual e cinema narrativo" (1975), da britânica Laura Mulvey, cuja publicação inicial foi na obra, já esgotada, A experiência do cinema (2008), organizada por Ismail Xavier. Considerando a época de lançamento e a disponibilidade atual, a opção por republicá-los é de total pertinência. Outro artigo, anteriormente traduzido, é o "Literatura" (1999), da indiana Gayatri Chakravorty Spivak, publicado no Cadernos Pagu, em 2002.

Exceto esses três textos, todos os outros se tratam de traduções inéditas para o português, realizadas, também, pelas organizadoras e por Luciana Deplagne, Rita Schmidt, Sandra Almeida, Susana Funck, Cintia Schwantes, Eliane Campello, além de Alcione Cunha da Silveira, Amanda Prado, Claudia Santos Mayer, Eliane Tejera Lisboa, Laureny Aparecida Lourenço, Maria Isabel de Castro Lima, Marina Andrade, Matias Corbett Garcez, Raquel D’Elboux Nunes, tatiana nascimento, Cila Ankier, João Luiz Vieira e Rachel Gorestein.

O fato de serem produções que se encontravam dispersas e, a maioria, até então sem tradução e circulação no país, abria uma fenda entre as obras e o acesso das/os pesquisadoras/es que não leem na língua original das referências. Ao tempo em que o projeto traduz e compila esses textos, preenche, também, o hiato que havia no trabalho acadêmico de tradução com essa perspectiva, favorecendo, assim, a mobilidade dos debates feministas. Como mesmo frisam as organizadoras, o referencial traduzido contempla tanto as discussões mais contemporâneas - a exemplo do queer, do feminismo material e da ecocrítica - quanto as consideradas clássicas. Traduções da Cultura... se apresenta, certamente, como um trabalho inaugural, que se tornará de leitura "obrigatória" para pesquisadoras/es atuantes ou em formação.

Cabe, ainda, mencionar a interdisciplinaridade que perpassa não somente a prática crítico-feminista, no seu aspecto metodológico, mas o conjunto dos ensaios que compõe a obra. São produções que tratam das questões de gênero na esteira da crítica literária, do cinema, das ciências sociais, da antropologia, da geografia, dos estudos culturais e da 
ecologia, em outros termos, nas ramificações da cultura. As mandalas da tela No jardim elétrico - que ilustram primorosamente a capa -, da artista plástica alagoana Marta Emília, sugestionam as interconexões e expansões que dizem respeito à crítica feminista e seus desdobramentos.

Os ensaios, artigos e capítulos foram distribuídos em quatro partes - aqui, chamo-as de quatro tempos -, tendo em vista os seus contextos de produção. Entretanto, destaco, como fazem as organizadoras, que, embora haja uma demarcação cronológica, o tempo não é linear e a construção de novos argumentos não corresponde ao apagamento das formulações anteriores. No decorrer da leitura, não restam dúvidas quanto ao diálogo constante entre textos, teorias e épocas. É uma trajetória em palimpsesto, para lembrar um argumento de Greta Gaard - contrário à noção de ondas -, num ensaio que integra a antologia.

O primeiro tempo é o dos anos 1970. Os textos desse período foram caracterizados como "rotas de entrada" para o desenvolvimento teórico-crítico do feminismo. "Quando da morte acordamos: a escrita como re-visão", lançado em 1971 pela poeta e crítica estadunidense Adrienne Rich, é o artigo que abre essa primeira parte. A escolha é significativa, já que, conforme Susana Bornéo Funck (2017, p. 88), no comentário que segue a tradução, esse foi um dos grandes clássicos da crítica contemporânea, sendo "[...] responsável pelo ímpeto revisionista que passa a caracterizar a teoria literária e cultural a partir das décadas finais do século XX, tendo suscitado importantes questionamentos sobre o cânone literário e a relação entre literatura e política".

Embora não haja dúvidas quanto à contribuição das produções desse contexto para a consolidação de discursos contra-hegemônicos voltados ao papel da mulher na história, na cultura e na psicanálise, é notório e amplamente questionado - inclusive, pelos artigos das décadas ulteriores - o caráter de unificação, naturalização e universalização da mulher. Nesse sentido, são representativos os já mencionados ensaios de Ortner e de Mulvey, do mesmo modo que "O riso da Medusa" (1975), da dramaturga, poeta e crítica argelina Hélène Cixous, e "Infecção na sentença: a escritora e a ansiedade de autoria", capítulo de The Madwoman in the Attic (1979), das estadunidenses Sandra Gilbert e Susan Gubar.

O segundo tempo compreende os anos 1980 e é intitulado "Da crítica à autocrítica". Se, na década anterior, entre outras questões, os debates giraram em torno das representações da mulher pelos discursos hegemônicos, agora, o olhar crítico é para a própria crítica feminista. É isso que a estadunidense Annette Kolodny faz no artigo "Dançando no campo minado: algumas observações sobre a teoria, a prática e a política de uma crítica literária feminista" (1980), ao mapear a trajetória, definir metodologias e constatar o campo minado onde as feministas são obrigadas a dançar para sobreviverem. Essa autocrítica favoreceu, especialmente, o reconhecimento do gênero como uma categoria de análise e, mais que isso, a desestabilização das categorias de gênero, por serem consideradas mantenedoras da heterossexualidade compulsória, segundo principia a francesa Monique Wittig, no seu polêmico "O pensamento straight" (1980), referência para a teoria queer.

Esse momento é igualmente fértil para a visibilidade das vozes negras e das mulheres do terceiro mundo, e, nesse aspecto, o texto "Sob os olhos do ocidente: estudos feministas e discursos coloniais" (1986), da indiana Chandra Talpade Mohanty, é figurativo. A tradução do capítulo introdutório "Quem tem medo de Virgínia Woolf? Leituras feministas de Woolf", da norueguesa Toril Moi, publicado no livro Sexual/Textual Politics (1985), por sua vez, contribui com a discussão sobre os processos de leitura e a perspectiva desconstrucionista de Derrida para a análise crítico-feminista. O ensaio que fecha a seção é "O 'risco' da essência" (1989), da estadunidense Diana Fuss, reforçando o diálogo entre os textos e as épocas, ao reler o conceito de essencialismo e defender a sua presença sob diferentes roupagens, inclusive, a do próprio construcionismo. 
Os ensaios "O olhar oposicional: espectadoras negras" (1992), da estadunidense bell hooks, "'Além' do gênero: a nova geografia da identidade e o futuro da crítica feminista" (1994), da também estadunidense Susan Stanford Friedman, "Literatura" (1999), de Spivak, e "Repensando, a partir do feminismo, os estudos literários latino-americanos" (1999), da cubana Nara Araujo, exemplificam o percurso "do gênero às suas intersecções", dos anos 1990. Esses trabalhos dão ênfase à diferença, às especificidades históricas e às questões pós-coloniais. Além disso, nessa década, as teorias pós-estruturalistas exercem forte influência no pensamento feminista e os Estudos Queer ganham expressão, sinalizando continuidade e ruptura com as definições precedentes. Esse terceiro tempo conta, da mesma forma, com os ensaios "Queer(izar) a escritora - Loca, escritora y chicana" (1991), da estadunidense Gloria Anzaldúa, e "Queer" (1996), da australiana Annamarie Jagose.

Alguns debates investidos nos anos 1990 são retomados nos 2000 , tempo de "novas topografias teórico-críticas", como é o caso dos ensaios "Não sou uma mulher? Revisitando a interseccionalidade" (2004), das inglesas Avtar Brah e Ann Phoenix, "Regulações de gênero" (2004), da estadunidense Judith Butler, e "A epistemologia do sul, a colonialidade de gênero e o feminismo latino-americano" (2010), da hondurenha Breny Mendoza, porém, com algumas (des)construções: o conceito de descolonialidade e o gênero como uma derivação de normas reguladoras, por exemplo. Essa última parte do livro traz, ainda, outras intersecções: o pós-humanismo e a ecologia, a partir de "O manifesto das espécies companheiras - cães, pessoas e alteridade significante" (2003) e do artigo "Novos rumos para o ecofeminismo: em busca de uma ecocrítica mais feminista" (2010), respectivamente, das estadunidenses Donna Haraway e Greta Gaard.

Obviamente, todas as teorizações, os conceitos e as argumentações mobilizados nos ensaios selecionados não cabem no escopo desta resenha. São abordagens a perder de vista, num constante ir e vir palimpséstico. Além da pertinência conjuntural do lançamento, Traduções da Cultura... apresenta outro valor simbólico: é a última publicação com o selo da Editora Mulheres, o que ganha contornos especiais, não somente pelo trabalho monumental de resgate e visibilidade de obras de escritoras do passado, empreendido pela editora, mas por esse encerramento coincidir com a despedida da idealizadora e pesquisadora memorável, Zahidé Lupinacci Muzart.

Brandão, Cavalcanti, Costa e Lima revelam: "Esperamos que esta publicação gere um impacto positivo nos vários contextos de pesquisa em que as perspectivas feministas e dos Estudos de Gênero e queer estejam presentes, tanto nos Estudos Literários e Culturais, quanto nas áreas de Ciências Humanas e Sociais" (BRANDÃO et al, 2017, p. 17). E eu, seguramente, afirmo que o impacto não existirá apenas nas pesquisas. Na vida de certas/ os pesquisadoras/es - especialmente as/os principiantes - a obra será tão valiosa quanto o livro-amante de Clarice Lispector, na sua felicidade clandestina.

\section{Referências}

BRANDÃO, Izabel; CAVALCANTI, Ildney; COSTA; Claudia de Lima; LIMA, Ana Cecília Acioli. (Orgs.). Traduções da Cultura: perspectivas críticas feministas (1970-2010). Florianópolis: EDUFAL; Editora da UFSC, 2017.

BRANDÃO, Izabel et al. "Apresentação". In: BRANDÃO, Izabel et al (Orgs.). Traduções da Cultura: perspectivas críticas feministas (1970-2010). Florianópolis: EDUFAL; Editora da UFSC, 2017, p. 15-61.

FUNCK, Susana Bornéo Funck. "Adrienne Rich (1929-2012): uma cética apaixonada". In: BRANDÃO, Izabel et al (Orgs.). Traduções da Cultura: perspectivas críticas feministas (1970-2010). Florianópolis: EDUFAL; Editora da UFSC, 2017, p. 85-90 
[Recebida em 14/1 1/2017 e aceita em 19/03/2018]

Edilane Ferreira da Silva' 'Universidade Federal de Alagoas, Programa de Pós-Graduação em Letras e Linguística, Maceió, AL, Brasil

Edilane Ferreira da Silva (edilaneferreira@msn.com) é mestra em Ecologia Humana e Gestão Socioambiental. Atualmente, cursa doutorado em Estudos Literários no Programa de Pós-Graduação em Letras e Linguística da Universidade Federal de Alagoas (UFAL), desenvolvendo pesquisa sobre as representações e inter-relações envolvendo homens, mulheres e natureza nos contos de fadas de Marina Colasanti, a partir da ecocrítica feminista. Integra, também, o Grupo Mare\&Sal Estudos e Pesquisas Interdisciplinares.

(iD) 0000-0002-6800-613X. 